\title{
Processing letters in words at different levels
}

\author{
HARVEY H. C. MARMUREK \\ University of Guelph, Guelph, Ontario, Canada
}

\begin{abstract}
Subjects indicated whether two letters, two words, or a letter and the first letter of a word were the same. Letter targets were matched more quickly than word targets when the stimuli were presented simultaneously. When the target and comparison stimuli were separated by a 3-sec interval, word targets were matched more quickly than a letter and a letter in a word. It was also shown that the physical similarity of the targets and comparison stimuli had a greater effect in the simultaneous matching conditions. These findings are consistent with a model of word processing in which letters are individually compared prior to word identification at a physical level of processing. At a higher level of processing, words may be encoded as a unit, and the identification of the letters within the word may require a decoding of the word unit.
\end{abstract}

In a recent review of studies of reading, Bradshaw (1975) concluded that the perceptual unit of a word is larger than the individual letter. The qualification that the unit may differ as task demands change failed to specify how those demands influence the processes underlying word perception. The goal of the present paper is to examine how task demands affect those processes in determining the role of the letter in word perception.

Posner (1969) has suggested two levels of processing that might be involved in word perception. Those processes were isolated by comparing the reaction times to decide whether two letters had the same name under conditions where the letters were physically similar or different. Physically similar letters (AA) were identified more quickly than physically different letters ( $\mathrm{Aa}$ ), leading Posner to conclude that the identification could be based on processing at either a low physical level or a higher order name level.

It is possible that the unit of word perception is determined by the level at which a word is processed. Reicher (1969) and Wheeler (1970) have shown that a letter was recognized more accurately when embedded in a word than when presented in isolation. This wordsuperiority effect suggests that word perception is not the result of independent processing of the constituent letters. The effect, however, is eliminated when subjects vocalize the stimuli (Mezrich, 1973), indicating that a change in the type of processing leads to a change in

This research is based on a dissertation submitted to the Department of Psychology, the Ohio State University, in partial fulfillment of the requirements for the PhD degree. The author would like to express his gratitude to his advisor, Neal F. Johnson, and the other members of the Reading Committee, Delos D. Wickens and Harvey G. Shulman, for their advice and support. Also, he would like to thank Rod Barron and E. C. Dalrymple-Alford for their helpful comments on earlier versions of this paper. Requests for reprints should be sent to Harvey H. C. Marmurek, Department of Psychology, University of Guelph, Guelph, Ontario, Canada. the role of letters in a word. Furthermore, Thompson and Massaro (1973) have shown that visual similarity is a significant factor under conditions producing a letter-superiority effect, but not under conditions leading to a word-superiority effect. Since Posner (1969) has suggested that visual similarity effects are present at the physical level of processing, it might be that letters are the units of word perception at the physical level and that a group of letters (or the word itself) is the unit at a higher order level.

This levels-of-processing hypothesis is compatible with two otherwise contradictory outcomes. Eichelman (1970) found that the time taken to identify two simultaneously presented words as identical increased as the length of the words increased. The implication is that component letters are the units of processing. Johnson (1975), however, found that word length did not significantly affect word matching when the stimuli were presented at different points in time, a finding which suggests word identification is not the result of individual letter processing. The critical methodological difference between the Eichelman (1970) and Johnson (1975) studies may have been the temporal relationship between the to-be-compared stimuli. Posner, Boies, Eichelman, and Taylor (1969) have shown that the advantage of a physical match over a higher order match was not significant when a 2-sec delay intervened between the test items. They suggested that a physical encoding may become less salient over time, while the higher order code increases in efficiency. In that case, the temporal conditions of the Eichelman (1970) study provided for a physical basis of decision which was less salient in the Johnson (1975) study. This is consistent with the levels-of-processing hypothesis that, at a physical level of encoding, letters are individually processed before a word is identified, whereas at a higher order level of encoding, individual letter identification follows the processing of a word as a unit.

The present experiment was designed to test the levels-of-processing hypothesis by extending the Johnson 
(1975) study to include identifications under simultaneous conditions. In the Johnson (1975) study, subjects studied either a letter or a word target and indicated whether that target was in a display. The display was either a letter or word, so that for letter targets the match could be between two single letters or between a single letter and a letter within a word. Johnson (1975) found that two words were matched as quickly as two single letters, and that both of those matches were carried out more quickly than a match between a single letter and a letter in a word. If those results are due to a higher order level of processing, then under conditions of physical processing afforded by simultaneous presentations of a target and display, letter targets should be identified more quickly than word targets. To test whether simultaneous presentation of test items did lead to more physical processing than delayed presentations, the physical similarity of those items was varied. It was predicted that physical similarity effects would be more pronounced under conditions of simultaneous presentation.

\section{METHOD}

\section{Design}

Although the guiding hypothesis required a comparison of decision latencies to match two words, two letters, and a letter to a letter in a word, it is possible that differences among those conditions might result from differential amounts of lateral masking (Townsend, Taylor, \& Brown, 1971). Thus, conditions were included to equate for the number of characters in a display by presenting letters along with asterisk masks in the conditions where letters were targets. There were four target/comparison conditions: (1) an isolated letter target and a comparison word, where the target, if present, would match the first letter of the word; (2) a masked letter and a word; (3) two words; and (4) two isolated letters. Each of these conditions was tested under the eight conditions defined by the factorial combination of the following variables: the interval between the target and the comparison item ( 0 or $3 \mathrm{sec})$; the physical formats of the target and the comparison item (same case vs. different case), and the correct response ("yes" vs. "no"). The resulting 32 conditions are shown in Table 1. Each subject was tested in each condition four times during an experimental session, yielding 128 observations per subject.

The trials in a session were blocked by levels of target/comparison condition and the interval between the target and the comparison item. The order of testing the target/comparison conditions was counterbalanced across subjects, and the order of testing a given interval for each of those conditions was also counterbalanced. The two correct responses were tested equally often, and the order of those responses was randomized with the constraint that no more than three consecutive responses were of the same type. Within each block of trials, both the target and comparison were in the same case on half of the trials and in different cases on the other half.

\section{Materials}

The stimuli were typed in pica type on index cards so that all stimuli would be centered in the visual field. In the 0-sec delay conditions, items appeared one above the other and the top item was designated as the target. In the 3-sec delay conditions, only one item was typed per card and two separate cards had to be used, the first one being designated as the target. The horizontal angles subtended by the stimuli on a card were $15 \mathrm{deg}$ for single letters and $59 \mathrm{deg}$ for four-character displays. The vertical angle for the displays used in the 3-sec delay condition was $15 \mathrm{deg}$ and was $35 \mathrm{deg}$ in the 0 -sec delay conditions.

All the words used were four-letter monosyllabic words with a mean frequency of 76 per million (Kucera \& Francis, 1967). The letters used on letter-target trials were selected from the first letter pairs of words used on word/word trials. For example, if a given word/word pair was MILE-MILE, a given letter/word pair would be M-MILE, and the same was true for TILE-MILE and T-MILE. The particular words and letters were selected so that the probability of confusing their uppercase forms was less than .01 (Townsend, 1971).

When letter targets were compared to the initial letter in a word and the correct response was "no," the letters were chosen so that if the letters were followed by the last three letters of the comparison word, a word would result. Thus, G-MILE would not be used while T-MILE would. On the "no" trials for word/word pairs, precautions were taken to discourage subjects from comparing a single pair of letters. Specifically, across the eight "no" trials for each word/word block, two pairs had no letters in common, two had one common letter, two had two, and two shared three letters. Examples of these pairs are NICE-LAMP (0-overlap), GRIM-TRUE (1-overlap), JAIL-PAIR (2-overlap), and LIVE-LOVE (3-overlap).

\section{Procedure}

Each subject was tested in one experimental session lasting about $1 \mathrm{~h}$. They were given preliminary instructions as to their task, namely, to indicate whether two stimuli had the same name. The definition of same name was illustrated with several examples of letters and words in the same and different cases. Then the subject was told of the various target/comparison conditions and was given four examples of each requiring a yes response and four where no was correct. Finally, the subject was told of the temporal variable and given eight more practice trials, four in the 0 -sec delay condition and four in the 3-sec delay condition.

A block of trials began with the experimenter describing the block in terms of its target/comparison condition and target/comparison interval. Each trial began when the experimenter said "Ready," and then initiated the displays in a Scientific Prototype two-channel tachistoscope. In the 0-sec delay conditions, subjects saw a noise field of random letters for $3 \mathrm{sec}$, the target and comparison simultaneously for $1 \mathrm{sec}$, and then the noise field. In the 3-sec delay conditions, the subject saw the following sequence: a noise field for $3 \mathrm{sec}$, the target for $1 \mathrm{sec}$, the noise field for $3 \mathrm{sec}$, the comparison stimulus for $1 \mathrm{sec}$, and the noise field. The subject was asked to respond as quickly as possible, but at no sacrifice to accuracy, by pressing one of two buttons corresponding to yes and no. The relationship between button position and correct response type was counterbalanced across subjects. The subject's response stopped a Hunter timer initiated by the comparison stimulus, and the experimenter recorded the latency of the response and whether it was correct. Subjects were given a 10 -sec rest between trials and a 1-min rest between blocks.

\section{Subjects}

Sixty-four introductory psychology students at the Ohio State University volunteered to serve as subjects. All had normal or corrected vision.

\section{RESULTS}

\section{Error Rates}

The mean error rates are shown in Table 1. An analysis of variance on those means revealed two significant effects: a main effect of Case $[F(1,63)=8.85$, $\mathrm{p}<.01, \mathrm{MSe}=.111]$ and the Case by Response inter- 
Table 1

Mean Percent Errors in the 32 Conditions

\begin{tabular}{|c|c|c|c|c|c|}
\hline \multirow[b]{2}{*}{ Format } & \multirow[b]{2}{*}{ Interval } & \multicolumn{4}{|c|}{ Target/Comparison Pair } \\
\hline & & $\begin{array}{l}\text { Letter/ } \\
\text { Word }\end{array}$ & $\begin{array}{c}\text { Masked } \\
\text { Letter/ } \\
\text { Word }\end{array}$ & $\begin{array}{l}\text { Word/ } \\
\text { Word }\end{array}$ & $\begin{array}{l}\text { Letter/ } \\
\text { Letter }\end{array}$ \\
\hline & \multicolumn{5}{|c|}{ Yes Response } \\
\hline Same & $\begin{array}{l}0 \\
3\end{array}$ & $\begin{array}{l}1.1 \\
3.1\end{array}$ & $\begin{array}{l}2.3 \\
1.1\end{array}$ & $\begin{array}{r}.4 \\
1.9\end{array}$ & $\begin{array}{l}1.9 \\
2.7\end{array}$ \\
\hline \multirow[t]{2}{*}{ Different } & $\begin{array}{l}0 \\
3\end{array}$ & $\begin{array}{l}4.3 \\
7.0\end{array}$ & $\begin{array}{l}4.7 \\
3.5\end{array}$ & $\begin{array}{l}3.1 \\
1.5\end{array}$ & $\begin{array}{l}5.1 \\
3.1\end{array}$ \\
\hline & \multicolumn{5}{|c|}{ No Response } \\
\hline Same & $\begin{array}{l}0 \\
3\end{array}$ & $\begin{array}{l}3.9 \\
2.3\end{array}$ & $\begin{array}{l}4.3 \\
1.1\end{array}$ & $\begin{array}{l}1.1 \\
2.7\end{array}$ & $\begin{array}{l}3.1 \\
1.9\end{array}$ \\
\hline Different & $\begin{array}{l}0 \\
3 \\
\end{array}$ & $\begin{array}{l}2.3 \\
1.1 \\
\end{array}$ & $\begin{array}{l}4.3 \\
2.3\end{array}$ & $\begin{array}{l}4.7 \\
3.1\end{array}$ & $\begin{array}{r}.4 \\
2.3\end{array}$ \\
\hline
\end{tabular}

action $[F(1,63)=9.17, p<.01, \mathrm{MSe}=.107]$. These effects show that more errors occurred when the cases of the target and display were different than when they were the same, and that this effect held only for "yes" responses. The experimental conditions were rank ordered by mean error rate and mean correct reaction time. The value of rho computed from these rankings was .24 , and the relationship of the rankings was not significant $[\mathrm{t}(30)=1.36, \mathrm{p}>.05]$. There is thus no evidence for a speed-accuracy tradeoff in this study and, since the levels-of-processing hypothesis makes predictions about reaction times, all further analyses reported will be those carried out on the mean correct latencies.

\section{Masking Effects}

The condition in which masked letters were compared to the first letter of a word was included to control for the possibility of differential lateral masking in the isolated-letter/word and word/word conditions. To determine if differential masking was present, the reaction times in the isolated-letter and masked-letter conditions were subjected to an analysis of variance. That analysis showed that the effect of masking was not significant $[\mathrm{F}(1,63)=.04, \mathrm{p}>.05, \mathrm{MSe}=24,693.9]$, and that none of the interactions involving the target/comparison condition factor were significant. Any differences between the isolated-letter/word and word/word conditions, therefore, may not be attributed to differential lateral masking, although the asterisk masks may not be as effective as other character masks (Estes, Bjork, \& Skaar, 1974). Nonetheless, Townsend et al. (1971) have shown that lateral masking effects are negligible in the initial position of a letter string.

\section{The Letter/Word and Word/Word Conditions Compared}

The 16 means formed by the isolated-letter/word and word/word conditions, and shown in Figure 1, were subjected to a 2 by 2 by 2 by 2 analysis of variance.
Three main effects were significant at the .01 level: Interval $[F(1,63)=1,055.04, M S e=21,827.8]$, Response Type $[\mathrm{F}(1,63)=36.32, \mathrm{MSe}=20,082.6]$, and Physical Format $[\mathrm{F}(1,63)=68.36, \mathrm{MSe}=6,962.7]$. These effects indicate that reaction times were faster for 3-sec delay conditions, "yes" responses, and items typed in the same case.

The analysis revealed four significant first-order interactions. The Target/Comparison by Interval interaction yielded $F(1,63)=52.17, \quad \mathrm{p}<.01, \quad \mathrm{MSe}=14,434.8$, showing that a letter was matched to the first letter in a word faster than a word to a word when the items were presented simultaneously, but the reverse occurred when a delay intervened between the comparison items. Separate analyses showed that letter targets were significantly faster than word targets at the 0 -sec delay $[F(1,63)=25.03, p<.01, \mathrm{MSe}=6,888.3]$, and that word targets were faster at the 3-sec delay $[F(1,63)=8.44, p<.01, \mathrm{MSe}=4,894.5]$.

The other significant first-order interactions were Target/Comparison by Physical Similarity $[F(1,63)=$ 9.40, MSe $=3,149.9$ ], Interval by Physical Similarity $[\mathrm{F}(1,63)=33.49$, MSe $=6,149.3]$, and Response Type by Physical Similarity $[F(1,63)=52 \cdot 22, \mathrm{MSe}=6,141.1]$. All of these interactions were significant at the .01 level and suggest the following limitations to the effect of physical similarity: The effect is greater in the word/word condition; it decreases as a delay is introduced between comparison items; the effect is greater for "yes" responses. The latter two restrictions in the physical similarity effect have been reported by Posner et al. (1969). The Target/Comparison by Interval by Response interaction was significant $[F(1,63)=16.62$, $\mathrm{p}<.01, \mathrm{MSe}=7,762.5]$. That interaction may have resulted from the finding that latencies for the word/word condition were faster than for the

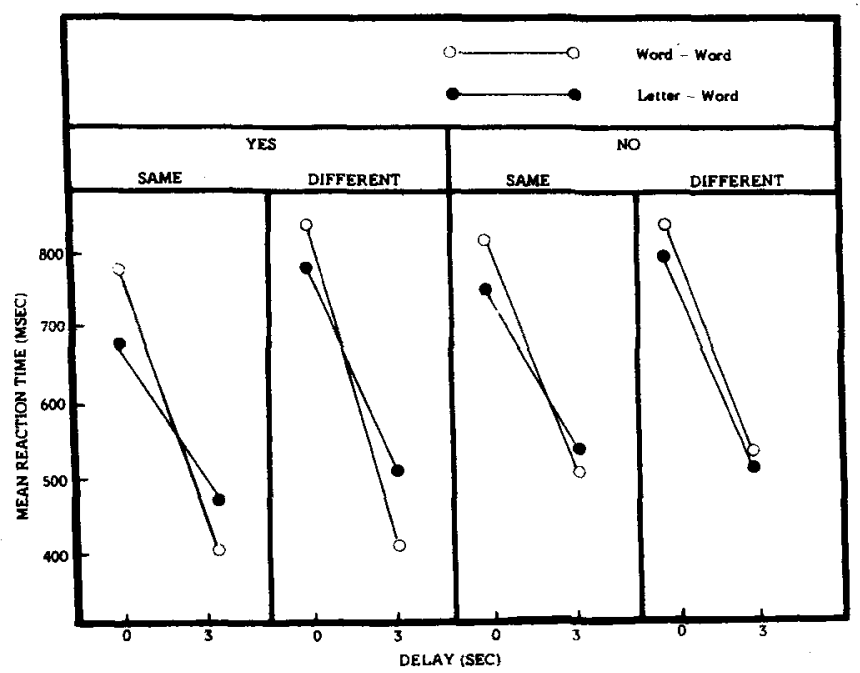

Figure 1. Mean reaction times for the letter/word and word/word analysis. Yes and no refer to response type, same and different to case similarity. 
letter/word condition in the 3-sec delay conditions for "yes" responses but not for "no" responses.

\section{The Effect of Overlap}

The mean reaction times for "no" responses as a function of the number of letters two different words had in common are shown in Figure 2 for both the 0 -sec and 3-sec interval conditions. An analysis of variance was performed on those items and it showed that both the effects of Interval and Overlap were significant at the .01 level $[F(1,63)=340.68, \mathrm{MSe}=30,232.7$ and $F(3,189)=36.81, \mathrm{MSe}=14,143.9$, respectively $]$. These effects show that reaction times increased as overlap increased, and that they were longer in the 0-sec interval conditions. The interaction of the factors was also significant $[\mathrm{F}(3,189)=5.55, \mathrm{p}<.01, \mathrm{MSe}=12,769.8]$. This interaction suggests that the impact of overlap was greater when the target and display were presented simultaneously.

Further support for this suggestion was obtained in a trend analysis of the functions in Figure 2. The linear component of both functions was significant $[F(1,189)=56.23, \quad p<.01$ and $F(1,189)=6.93$, $\mathrm{p}<.01$ for the simultaneous and delayed conditions, respectively]. The linear component of the 0-sec delay function accounted for $97 \%$ of the variance due to overlap, whereas the linear component of the $3-\mathrm{sec}$ delay function accounted for $58 \%$ of the variance. The quadratic component of the 0 -sec function was not significant $[F(1,189)=.86, p>.05]$, whereas the

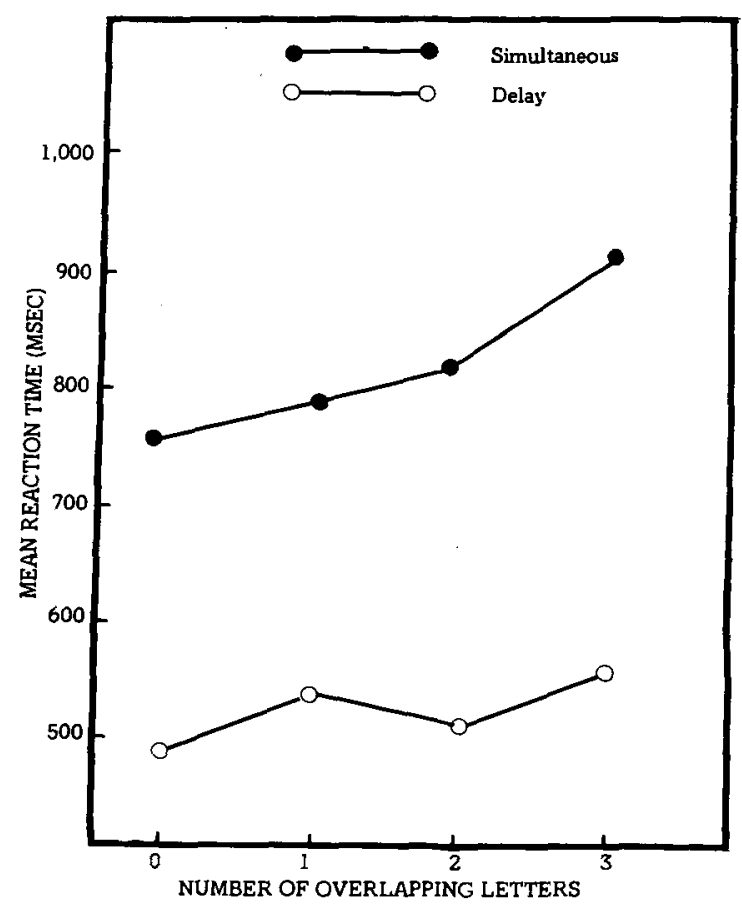

Figure 2. Mean reaction times as a function of overlap on "no" trials of word/word comparisons.

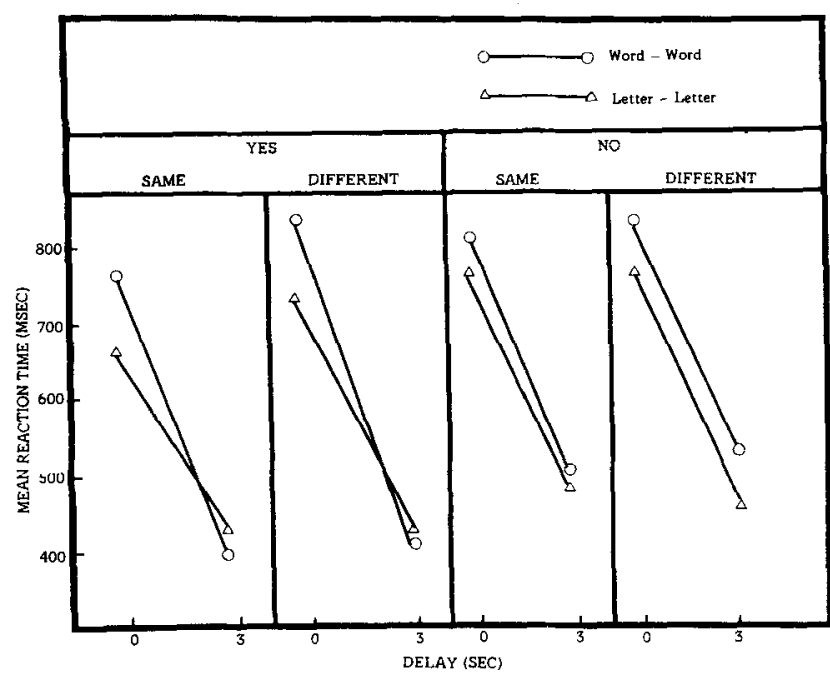

Figure 3. Mean reaction times for the word/word and letter/letter analysis. Yes and no refer to response type, same and different to case similarity.

quadratic component of the 3-sec delay function was significant $[F(1,189)=4.36, p<.05]$. To determine the source of the quadratic component, a Duncan's multiple range test was carried out. The analysis showed that when three letters overlapped, latencies increased, but there were no differences among the latencies for the other three levels of overlap.

\section{A Comparison of the Letter/Letter and Word/Word Conditions}

It has been shown that the time advantage in identifying a letter in a word over identifying the whole word changes with the interval between the target and the word display. A condition in which two single letters were compared was included to determine whether that effect is confined to conditions in which letter targets are embedded in words. The means for the letter/letter and word/word conditions are plotted in Figure 3. An analysis of those means reaffirmed the earlier findings that responses were faster for 3-sec intervals $[\mathrm{F}(1,63)=1,037.45, \mathrm{p}<.01, \mathrm{MSe}=22,083.3]$, "yes" responses $[\mathrm{F}(1,63)=59.28, \mathrm{MSe}=14,189.3]$, and items in the same case $[\mathrm{F}(1,63)=54.96, \mathrm{p}<.01$, $\mathrm{MSe}=5,842.7]$. Furthermore, letter targets were identified more quickly than words $[\mathrm{F}(1,63)=21.78$, $\mathrm{p}<.01, \mathrm{MSe}=27,461.6]$. The Target/Comparison by Interval interaction was also significant $[F(1,63)=54.06$, $\mathrm{p}<.01, \mathrm{MSe}=14,330.8]$. That interaction suggests that the advantage of the letter/letter condition occurred only when the target and comparison items were presented simultaneously. Further analyses supported this suggestion. At the 0 -sec interval, the mean reaction times in the letter/letter and word/word conditions were 727 and $831 \mathrm{msec}$, respectively, and the difference was significant $[F(1,63)=69.28, p<.01]$. At the 3-sec interval, the reaction times were 488 and $476 \mathrm{msec}$, 
and the difference was not significant $[F(1,63)=.56$, $p>.05]$. This lack of a difference in identifying two letters and two words when they are separated in time was reported by Johnson (1975).

\section{DISCUSSION}

In the present study, the hypothesis that the level of processing determines the role of the letter in word processing was tested by examining the following two effects reported by Johnson (1975): (1) Two words were matched as quickly as two single letters, and (2) two words were matched more quickly than a single letter and the first letter in a word. In those experiments, Johnson (1975) presented the stimuli to be compared at different points in time, resulting in an interval during which subjects may have encoded the test item to some level at which physical information became ineffective as a basis for responding (Posner et al., 1969). It was predicted that under conditions where the physical information was more salient, namely, when simultaneous matching conditions were used, the letter-target conditions would result in faster latencies than word-target conditions.

Two findings suggest that simultaneous and delayed matching conditions did result in different bases for decisions. First, the effect of presenting the stimuli in the same or different physical format was greater under conditions of simultaneous matching. A second manipulation of physical similarity occurred on the "no" trials of word/word conditions in that the two different words shared up to three letters in common. The effect of letter overlap was greater in the simultaneous than in delayed conditions. The interactions of physical format and overlap with the interval factor indicated that more physical processing occurred in the simultaneous conditions. Although overlap did have an effect in the delayed matching task, an a posteriori analysis showed that the effect was due to the differences between three overlapping letters and all other levels of overlap. It may be that in the delayed condition subjects were naming the stimuli, since this is equivalent to a memory task (Rumelhart \& Siple, 1974). In that case, the overlap effect may be due to common articulatory mechanisms being invoked in the naming of the two different words.

The suggestion that the delayed task involved memory processes that the simultaneous task did not is consistent with the finding that reaction times were longer in the simultaneous conditions. This result, also reported by Kreuger (1970) and Posner et al. (1969), suggests that in the simultaneous task the subject encoded both the target and the comparison item, either serially or in parallel, and compared those encodings before responding. In the delayed task, only the comparison item had to be encoded before responding, and that encoding was compared to the previously encoded target. If the physical information in the target became less salient during the interval, then the comparison stimulus was required to be encoded at a level comparable to the level of the target item at the time of the decision. This level may have involved naming the comparison item.

If the level of processing does determine how letters in words are processed, then it must be shown that the processing of those letters is different in the simultaneous and delayed conditions. Two findings are important in supporting the levels-of-processing hypothesis. First, single letters were matched more quickly than words in the simultaneous conditions, while no difference was found in the delay conditions. The lack of a difference in the delay conditions replicates the finding by Johnson (1975) and suggests that subjects were comparing either letter-unit or word-unit patterns directly, since either a serial or parallel limited-capacity letter processing model would predict longer latencies for the word/word condition. Those models do account for the simultaneous conditions, suggesting that in the word/word conditions, individual letters were the units of comparison in the simultaneous conditions.

The second supportive finding was that whereas a letter within a word was matched more quickly than an entire word in the simultaneous conditions, the reverse held in the delayed conditions. The letter-target advantage in the simultaneous conditions suggests that letter processing did occur in the word/word condition, since more processing would be required for word/word comparisons leading to the longer latencies. The wordtarget advantage in the delayed conditions was also found by Johnson (1975), and suggests that additional processing occurred in the letter-target condition. It may be that this extra processing entailed a decoding of the word into its component letters, which were then matched to the target letter.

The results of the present study differed from those reported by Johnson (1975) for "no" responses in the delay condition, in that the word-target advantage over a letter within a word was eliminated. The target and comparison words used by Johnson in that condition were entirely different, whereas in the present study the number of overlapping letters varied from zero to three, and the elimination of the word advantage may be attributed to the long reaction times when the two different words shared three letters. If subjects were naming the words in the delay condition, the occurrence of a slight discrepancy in articulatory responses may have led subjects to analyze the words letter by letter. That is, the words would be subdivided into their components, as when a letter was searched for within a word. Hence, there would be no difference between the letter/word and word/word latencies on "no" trials of the delay condition. In the simultaneous condition, letters within words are matched more quickly than two words for both "yes" and "no" responses, indicating that in those conditions the letter/word decision does not require a decomposing of an identified word. 
If the present analysis is correct, then it may be concluded that letters in words may be directly processed prior to word identification at a physical level of processing and after word identification once the word has been named.

This level of processing model is similar to one presented by Estes (1975) to account for the inconsistency of familiarity effects in letter perception. Estes (1975) has shown that the context effect (perception of a letter in a word is more accurate than the perception of a letter in a nonword) is dependent upon the level at which a subject is processing the stimulus when the context is provided. At some levels, according to that model, letters may be processed independently of the context. That model is consistent with the implications of the present study that the relationship of a letter to the word in which it is embedded changes with the level to which the word is processed.

\section{REFERENCES}

Bradshaw, J. L. Three interrelated problems in reading: A review. Memory \& Cognition, 1975, 3, 123-134.

Eichelman, W. H. Familiarity effects in a simultaneous matching task. Journal of Experimental Psychology, 1970. 86. $275-282$.

Estes, W. K. The locus of inferential and perceptual processes in letter identification. Journal of Experimental Psychology: General, 1975, 104, 122-145.

Estes, W. K., Bjork, E. L., \& SKaAR, E. Detection of single letters and letters in words with changing vs. unchanging mask characters. Bulletin of the Psychonomic Society, 1974, 3, 201-203.
Johnson, N. F. On the function of letters in word identification: Some data and a preliminary model. Journal of Verbal Learning and Verbal Behavior, 1975, 14, 17.29.

KREUGer, L. E. Visual comparison in a redundant display. Cognitive Psychology, 1970, 1, 341-357.

KUCERA, H., \& FRANCIS, W. N. Computational analysis of present-day American English. Providence, R.I: Brown University Press, 1967.

Mezrich, J. J. The word superiority effect in brief visual displays: Elimination by vocalization. Perception \& Psychophysics, 1973, 13, 45-48.

PosNer, M. I. Abstraction and the process of recognition. In G. Bower (Ed.), Advances in Learning and Motivation, (Vol. 3). New York: Academic Press, 1969.

Posner, M. I., Boles, S. J., Eichelman, W. H., \& Taylor, R. L. Retention of visual and name codes of single letters. Journal of Experimental Psychology Monograph, 1969. 79. 1-16.

ReIcher, G. M. Perceptual recognition as a function of meaningfulness of stimulus material. Journal of Experimental Psychology, 1969, 81, 275-280.

Rumelhart, D. E., \& Siple, P. Process of recognizing tachistoscopically presented words. Psychological Review, 1974, 81, 99-118.

Thompson, M. E., \& Massaro, D. W. Visual information and redundancy in reading. Joumal of Experimental Psychology, 1973, 98, 49-54.

TOWNSEND, J. T. Theoretical analysis of an alphabetic confusion matrix. Perception \& Psychophysics, 1971, 9. 40-45

Townsend, J. T., TAYlor, S. G., \& Brown, D. R. Lateral masking for letters with unlimited viewing time. Perception \& Psychophysics, 1971, 10, 375-378.

WhEELER, D. D. Processes in word recognition. Cognitive Psychology, 1970, 1, 59-85.

(Received for publication February 26, 1976; revision received May 24,1976 .) 